\title{
AVALIAÇÃO DAS CARACTERÍSTICAS FECAIS DE CÃES SUPLEMENTADOS COM DIFERENTES FONTES E NÍVEIS DE EXTRATO DE YUCCA
}

(Evaluation of faecal characteristics of dogs supplemented with different levels of Yucca Extract) Alina S. Komarcheuski ${ }^{1}$, Tabyta T. Sabchuk ${ }^{1}$, Taís S. Bastos ${ }^{1}$, Nayara Ostapechen ${ }^{1}$, Aline Merchiori ${ }^{1}$,
Simone G. de Oliveira ${ }^{1}$

1Departamento de Zootecnia - Universidade Federal do Paraná, Curitiba-PR E-mail: alina.stadnik@yahoo.com.br

Resumo: Objetivou-se determinar a interferência do aditivo extrato de Yucca schidigera em diferentes concentrações e fontes comerciais (EYA vs EYB) nas características fecais de cães. Utilizaram-se 15 cães adultos da raça Beagle, distribuídos em delineamento em blocos ao acaso, totalizando 6 repetições por tratamento. Foram analisadas nas fezes a matéria seca fecal (MSf), produção fecal, amônia, escore, $\mathrm{pH}$ e odor fecal. Houve diferença nos valores de MSf, produção fecal e para odor fecal em ambos os testes realizados $(P<0,05)$. A concentração de $0,07 \%$ de EYA resultou em maior MSf e menor odor fecal em relação ao EYB.

Palavras-chave: aditivo; animais de companhia; saponina

Abstract: The objective of this study was to determinate the interference of the Yucca schidigera extract in different concentrations and commercial sources (EYA vs EYB) in faecal characteristics of dogs. Fifteen Beagle adult dogs were distributed in a randomized block design, totaling 6 replicates per treatament. Fecal dry matter (DMf), fecal production, ammonia, score, $\mathrm{pH}$ and fecal odor were evaluated in the faeces. There were differences in DMf, fecal production and fecal odor values in both tests $(P<0.05)$. The concentration of $0.07 \%$ of EYA resulted in higher DMf and lower fecal odor than EYB.

Keywords: additives; company animals; saponin

Introdução: A redução de odor das fezes de cães pode ser alcançada com adição de aditivos na dieta, como o extrato de Yucca schidigera. Esse aditivo pode reduzir o mau odor das fezes devido à presença de glicosídeos, como as saponinas e glicocomponentes. Esses compostos diminuem a excreção de amônia, inibindo a urease, que é uma das responsáveis pelo odor das fezes. Desse modo, o objetivo do estudo foi avaliar as características fecais de cães alimentados com dietas contendo diferentes concentrações e fontes comerciais de extrato de yucca.

Material e Métodos: Foram avaliados as características fecais de 15 cães adultos, da raça Beagle $(10,3 \pm 1,07 \mathrm{~kg})$. O experimento foi composto por 2 períodos com cinco dias de adaptação seguidos de um dia de colheita de fezes cada, totalizando 6 repetições. Os tratamentos consistiam em cinco dietas isonutritivas, sendo uma dieta controle com $0 \%$ de extrato de Yucca (DC), com $0,035 \%$ de extrato Yucca A $(0,035$ EYA), com $0,07 \%$ de extrato de Yucca $A(0,07 \mathrm{EYA})$, com $0,035 \%$ de extrato de Yucca B $(0,035$ EYB) e com $0,07 \%$ de extrato Yucca B $(0,07$ EYB). Foram avaliadas teor de matérias seca fecal (MSf), produção de fezes, escore $(1=$ fezes líquidas a 5 = fezes secas), concentração de amônia, $\mathrm{pH}$ fecal e odor fecal. A avaliação do odor fecal foi realizada por meio da comparação do odor em relação à dieta controle 
(padrão). O experimento foi analisado segundo delineamento em blocos ao acaso. Após comprovada a normalidade, os dados foram submetidos a ANOVA e as médias comparadas por Tukey a $5 \%$ de probabilidade. Os dados do teste de odor fecal foram analisados pelo teste Qui-quadrado $(P<0,05)$.

Resultados e Discussão: Houve diferença nos valores de MSf, produção fecal e para odor fecal em ambos os testes realizados $(P<0,05)$. Não houve diferença para os parâmetros de escore fecal, nitrogênio amoniacal e pH fecal, conforme tabela 1. A inclusão de $0,035 \%$ de EYA, quando comparada com às demais analisadas, provocou maior produção fecal e fezes úmidas. Em contrapartida, a concentração $0,07 \%$ de EYA reduziu a umidade das fezes.

Tabela 1. Valores de MSf, produção fecal, escore fecal, $\mathrm{NH}_{3}$ e $\mathrm{pH}$ das fezes de cães recebendo dieta controle (DC), $0,035 \%$ de Yucca B $(0,035 E Y B), 0,07 \%$ de Yucca B (0,07EYB), $0,035 \%$ de Yucca A (0,035EYA) e 0,07\% de Yucca A (0,07EYA).

\begin{tabular}{lccccccc}
\hline Item & DC & $0,035 E Y B$ & $0,07 E Y B$ & $0,035 E Y A$ & $0,07 E Y A$ & EPM & $P$ \\
\hline MSf (\%) & $42,1^{\text {ab }}$ & $41,7^{\mathrm{ab}}$ & $40,3^{\mathrm{b}}$ & $38,3^{\mathrm{c}}$ & $43,1^{\mathrm{a}}$ & 0,3745 & $<0,0001$ \\
Produção & $0,74^{\mathrm{ab}}$ & $0,74^{\mathrm{ab}}$ & $0,56^{\mathrm{c}}$ & $0,82^{\mathrm{a}}$ & $0,69^{\mathrm{b}}$ & 0,0183 & $<0,0001$ \\
fecal (g/d) & 4 & 3 & 4 & 3 & 4 & 0,0830 & 0,2113 \\
Escore & 4 & 0,1103 & 0,1210 & 0,1106 & 0,1213 & 0,0041 & 0,7114 \\
$\mathrm{NH}_{3}(\%)$ & 0,1053 & 7,19 & 7,18 & 7,00 & 7,25 & 0,0421 & 0,2666 \\
$\mathrm{pH}$ & 7,27 & 7,19 &
\end{tabular}

${ }^{1}$ Médias seguidas por letras distintas diferem pelo teste de Tukey $(P>0,05)$

P: Probabilidade

$\mathrm{NH}_{3}$ : Nitrogênio amoniacal

Em relação ao odor fecal as concentrações de 0,035\% e 0,07\% de EYA foram julgadas pelos avaliadores com melhor odor em relação à dieta contendo $0,035 \%$ EYB. O mesmo ocorreu quando a dieta isenta de extrato de yucca foi comparada a esta dieta. A adição de $0,07 \%$ de EYB mostrou-se semelhante.

O mau odor das fezes é constituído por compostos voláteis como amônia, aminas biogênicas, indóis, fenóis e ácidos graxos de cadeia ramificada. A proporção relativa desses compostos é influenciada pela composição da microbiota colônica, interações metabólicas entre bactérias, nutrientes disponíveis para fermentação, tempo de trânsito intestinal, e uma variedade de fatores ligados ao próprio indivíduo (NRC, 2006). Outros compostos que influenciam no odor das fezes não foram mensurados no presente estudo.

Conclusão: A concentração de $0,07 \%$ de EYA resultou em maior MSf e menor odor fecal em relação ao EYB.

Referências: NATIONAL RESEARCH COUNCIL - NRC. Nutrient Requirements of Dogs and cats. National Academy Press. Washington, 2006, 426p. 